Portland State University

PDXScholar

1983

\title{
SCL-90 characteristics of the borderline personality disorder in a day treatment setting
}

Jeananne Theresa Feagan

Portland State University

Follow this and additional works at: https://pdxscholar.library.pdx.edu/open_access_etds

Part of the Clinical Psychology Commons, Personality and Social Contexts Commons, and the Psychiatric and Mental Health Commons

Let us know how access to this document benefits you.

\section{Recommended Citation}

Feagan, Jeananne Theresa, "SCL-90 characteristics of the borderline personality disorder in a day treatment setting" (1983). Dissertations and Theses. Paper 3261.

https://doi.org/10.15760/etd.3252

This Thesis is brought to you for free and open access. It has been accepted for inclusion in Dissertations and Theses by an authorized administrator of PDXScholar. Please contact us if we can make this document more accessible: pdxscholar@pdx.edu. 
AN ABSTRACT OF THE THESIS OF Jeananne Theresa Feagan for the Master of Science in Psychology presented July 25, 1983.

Title: SCL-g0 Characteristics of the Borderline Personality Disorder in a Day Treatment Setting.

APPROVED BY MEMBERS OF THE THESIS COMMITTEE:

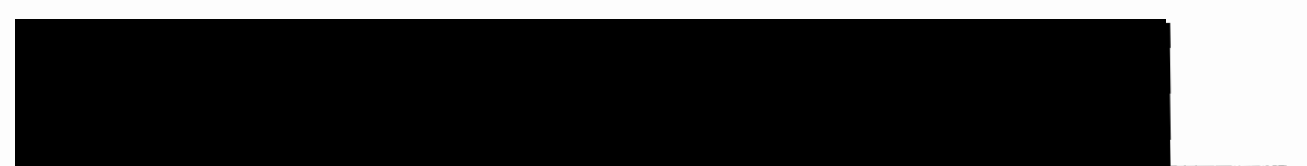

Chadwick Karr, Chairperson

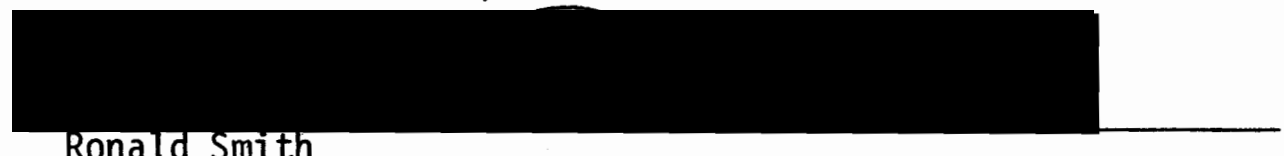

Ronald Smith

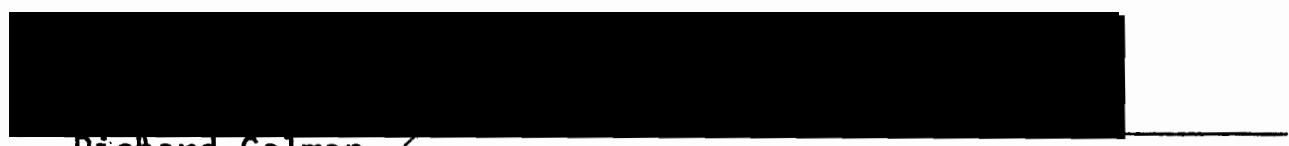

Richard Colman

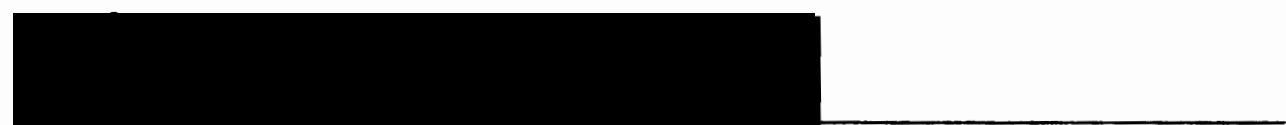

Peter Barbur

The current diagnostic category of Borderline Personality Disorder evolved from forty years of controversy as to its true nature. Now that systematic criteria have been identified for this disorder, structured psychological testing can be used to study its characteristics more closely.

The purpose of this present study was to examine test performance of the Borderline Personality Disorder on the Symptom Checklist (SCL-90). This investigation addressed whether the Borderline Personality Disorder has a distinctive profile on the SCL-90, and whether the profile is distinguishable in comparison with two other groups with mental disorders. 
The SCL-90 was administered to 135 patients in the Providence Day Treatment Program. The experimenter examined SCL-90 test results for three groups comprised of 52 Borderline Personality Disorders, 40 Schizophrenics, and 43 Major Affective and other personality disorders.

Five different discriminant analyses were performed in comparing the test results among the groups. Results were that discriminating characteristics for Borderlines vs. Schizophrenics are high Depression and similar Psychoticism, and for Borderlines vs. Major Affective/ other personality disorders are high Phobic Anxiety and similar Hostility. The three groups taken together were best discriminated by Phobic Anxiety, Hostility, Paranoid Ideation, and Depression. A single test item, "Feelings of Guilt," was found to be a significant discriminator of the Borderlines from the other groups when all test variables were considered.

Results indicated that the Borderline Personality Disorder exhibits both psychotic and neurotic characteristics and is caught up in a cycle of anger, guilt, and depression. 
SCL-90 CHARACTERISTICS OF THE BORDERLINE PERSONALITY DISORDER

IN A DAY TREATMENT SETTING

by

JEANANNE THERESA FEAGAN

A thesis submitted in partial fulfillment of the requirements for the degree of

MASTER OF SCIENCE

in

PSYCHOLOGY

Portland State University

1983 
TO THE OFFICE OF GRADUATE STUDIES AND RESEARCH:

The members of the Committee approve the thesis of

Jeananne Theresa Feagan presented July 25, 1983.

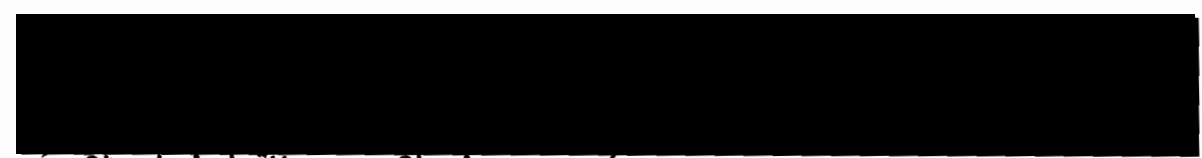

Chadwick Karr, Chairperson

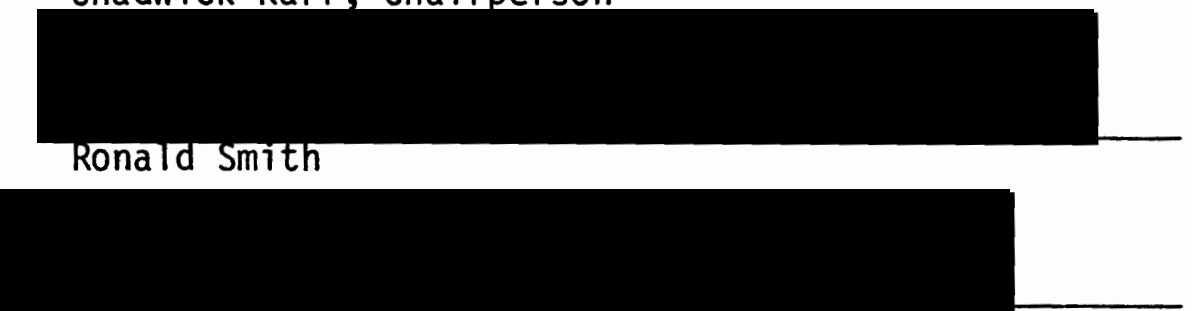

Richard Colman'

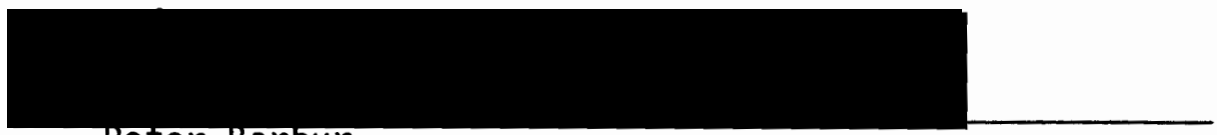

Peter Barbur

APPROVED:
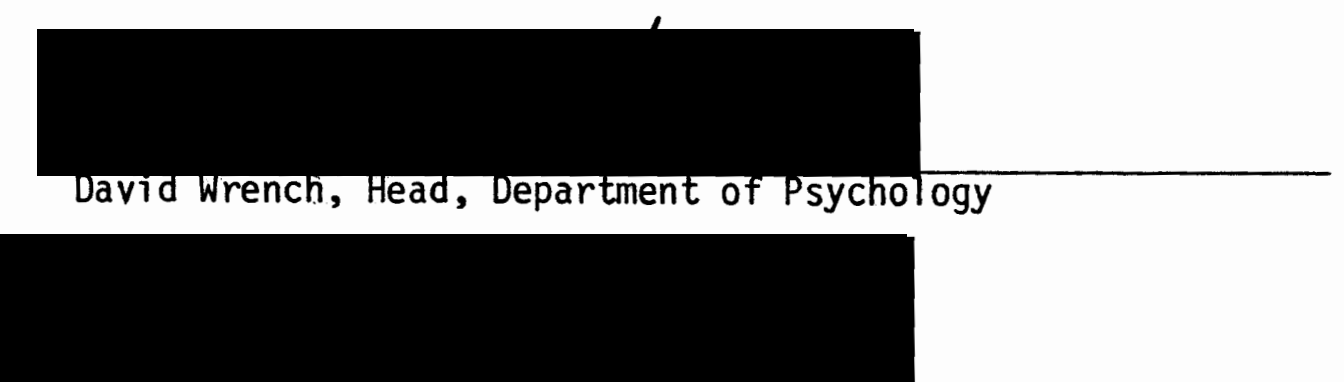

Stanley E. Rauch, Dean of Graduate Studies and Research 


\section{ACKNOWLEDGMENTS}

I would like to thank the administration of the Providence Day Treatment Program for allowing me access to the patient data for this study. Providence's Case Coordinator, Peter Barbur, M.S., made this project feasible for me by always being patiently available for my numerous questions. I am especially grateful to Peter for taking time out of his crowded schedule to act as a committee member and an invaluable clinical consultant.

Statistical consultation was provided to me by Dr. Barbara Stewart and Robert Tim Kopp. I thank both Barbara and Tim for rescuing me at the times when I thought I would certainly drown in a sea of ununderstandable computer printouts.

I would also like to thank my committee members, Dr. Ron Smith and Dr. Richard Colman. Both impressed me with their consistent concern and support, no matter what time I dropped in for help. The ir critical evaluations and contributions benefited me throughout this study's process.

My greatest thanks go to Dr. Chadwick Karr, without whom this study would not have been started or completed. Chad was my source of encouragement and enthusiasm throughout uncountable contacts. Although Chad's competence, knowledge, and professionalism mark him as a truly great educator, his unique gift lies in unquestionably regarding each individual as a delightful and worthwhile person capable of great things. Chad's attitudes greatly affected my progress in this study and continue to influence my personal life and the way I work with others.

My final thanks go to the many friends, particularly Cathy Hitchcock and Sandi Carter, who via odd-jobs, typing sessions, coffeebreaks, and general support, nurtured me through the final deadlines of this project. 
TABLE OF CONTENTS

\section{PAGE}

ACKNOWLEDGEMENTS .........................

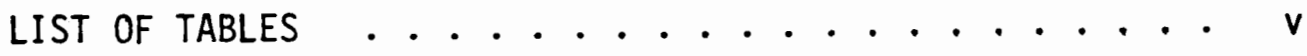

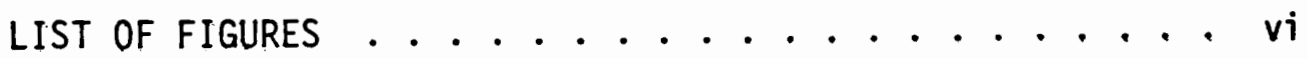

CHAPTER

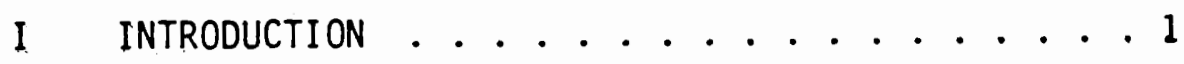

II PURPOSE OF STUDY . . . . . . . . . 10

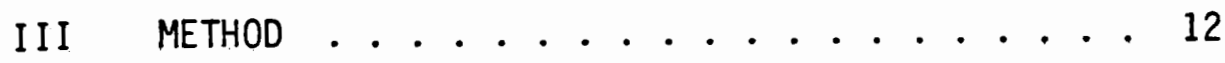

IV RESULTS ................. 17

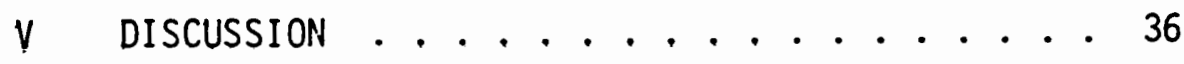

REFERENCES ................... 42 
LIST OF TABLES

TABLE

PAGE

I Sample Characteristics .......... 13

II Means and Standard Deviations ........ 17

II Male/Female Borderline Means ........ 20

IV Box's M Test Results ........... 21

V Borderlines vs. Schizophrenics Summary . . . . 23

VI Borderlines vs. Schizophrenics Classification . . 24

VII Borderlines vs. Other Summary . . . . . . . 25

VIII Borderlines vs, Other Classification ..... 27

IX Three Group Analys is Summary . . . . . . . 28

X Three Group Classification .......... 29

XI Means and Standard Deviations for Test Items . . 30

XI I Test Items Classification .......... 31

XIII Nineteen Variable Classification ....... 33 


\section{LIST OF FIGURES}

FIGURE

PAGE

1. Groups Compared on Mean SCL-90 Scores ....... 19

2. Borderline vs. Schizophrenic Discriminant

Function Scores Distribution . . . . . . 22

3. Borderline vs. "Other" Discriminant Function

Scores Distribution ........ . 26 
CHAPTER I

INTRODUCTION

The diagnosis of Borderline Personality Disorder currently included in the third and latest edition of the American Psychiatric Association's Diagnostic and Statistical Manual (1980) evolved from four decades of controversy over both characterization and categorization. The origins of the controversy can be traced to Deutsch (1942) who identified a type of personality disorganization fluid between neurosis and psychosis. She labeled this the "as if" personality referring to a lack of firm ego identification masked by seemingly appropriate social behavior. In England, Melanie Klein (1946) was investigating cases of developmental arrest from the perspective of an object-relations theory and in the process developed useful language in conceptualizing the condition. Knight (1953) then suggested that this "borderline state" was stable in its own right rather than transitory between neurosis and psychosis. Knight's criteria for the borderline state, with its accompanying descriptive ego weaknesses, provided a framework for clinicians, theoreticians, and psychometricians to inquire into the nature of the condition over the next thirty years.

Characteristics and Nature of the Borderline

The path of delineating the Borderline Personality Disorder has been strewn with confusion, in part because of the differing theoretical orientations of the observers. At the same time, it was only in approaching the condition from different fronts that a converging sense of the 
borderline person came forth. Studies which have made a major impact in this process are cited herein.

The borderline patient experienced many labels over the years. One of the most firmly held by New York clinicians during the 1960's was pseudoneurotic schizophrenic (Gunderson \& Singer, 1975). The studies of local originators of this concept provided clinical investigations supporting the conclusion that borderline persons suffer from an elusive form of schizophrenia (Hoch \& Polatin, 1949; Hoch \& Cattell, 1959; Hoch, Cattell, Strahl, \& Pennes, 1962). They saw in these persons subtle disorders of thought and association as well as pananxiety, panneurosis, and sexual perversity. A follow-up study done during this period found that twenty percent of the original patients investigated later did have a schizophrenic episode, and ten percent of those were chronic.

While borderline patients were being conceptualized as mild schizophrenics, other studies were going further to assess similarities in charterological styles and manifestations. Grinker, Werble, and Drye (1968) presented the first systematic empirical research, studying 51 hospitalized patients and defining 93 scale-point ego function variables. The common features identified for the borderline patients were a main affect of anger, interpersonal relationship deficits, anhedonia, and a generalized absence of self-identity. The Grinker et al. analys is also identified four subtypes of these patients from their pattern of characteristics. Type one borderlines were those lying close to the psychotic border and manifesting gross identity deficit and inappropriate behavior. These persons experienced anger and depression as a moderate but consistent orientation in their lives. In type two borderlines (also called the 
core borderline syndrome) relationships became the potent mirror of symptoms. Involvement with others was vacillating, and anger was acted out primarily in this sphere. Core borderline persons had inconsistent self-identity and their affect floated, sometimes quickly, between anger and depression. The third subtype of borderline identified resembled Deusch's "as if" personality, having appropriate adaptive behavior, and complementary relationships, but rigid and limited defense mechanisms. Type four borderline was seen to lie on the neurotic border exhibiting narcissistic tendencies, restricted affect, anxiety and depression. Overall, the Grinker et al. study was a landmark in borderline state research. It not only established a model for controlled, systematic investigations, but defined consistent characterological features of the patient group. Also, as a result of their delineation of the fourtype spectrum, heretofore speculative findings could be organized by theoreticians concerned with the borderline inquiry.

One of these theoreticians was Kernberg (1967) whose etiological conception of the borderline state is still viable among clinicians today. Kernberg, like Melanie Klein, looked to developmental arrest as the underlying cause of ego deficits. He postulated that patients with the borderline ego structures achieved a relatively individuated sense of self in early life in that they could distinguish self from others and experience object constancy. However, their development was arrested in the area of reintegrating feelings provoked in the subsequent stage of interacting with others and the emerging object world. For whatever reasons this developmental snag arose, the results were intolerable anxiety. Kernberg speculated that the infantile defense against this 
anxiety was to experience the self-other/object-world as all-good or all-bad. This: "splitting" was seen as the primary defense mechanism of the borderline ego structure. Other mechanisms included primitive idealization, projective identification, denial, omnipotence, and devaluation. In later writings Kernberg $(1975,1977)$ was not wedded to any specific conception of the ultimate etiology of the borderline state, but continued to view the condition's core characteristic to be the pathological personality organization. In contrast to sign and symptom criteria which are episode-oriented, Kernberg views the condition as a longitudinal process of long-term development resulting in a stable entity, albeit with symptomatic fluctuations.

Concurrent with studies addressing personality organization, character style, and schizophreniform disturbances, researchers al so focused on the affect of borderline patients as a uniquely distinguishable trait. D.F. Klein $(1967,1975)$ investigated effects of psychiatric medication on hospitalized patients. He identified a spectrum of disorders which seemed to exhibit characteristic responses to certain drugs while exhibiting varying affective symptoms. Klein felt that these atypical affective disorders were a distinct group comprised of several subtypes. These were called phobic anxious, emotionally unstable character disorders, and hysteroid dysphorics. It was argued that the affective vulnerabilities of these patients were the core psychopathological feature and that the characterological features focused on by other investigatore were only secondary phenomena.

Klein's research, as well as the other preceding studies whose orientation influenced the development of the concept of the borderline state, provided fertile ground for controversy. One question was simply 
"what is meant by borderline?" What had at one time been called a "wastebasket diagnosis" developed into a myriad of descriptive states and traits. Researchers often defined anew the borderline patient, without attempting to integrate past findings.

Another controversial question, congruent with the first, was whether the borderline condition was distinct unto itself. Researchers focusing on different attributes had created a full psychotic-neurotic/ mood-character disorder scale for consideration, Descriptive language was necessarily based on more established mental disorders. This dependence on familiar language, together with the frequent lack of overlap in findings, encouraged the criticism that the borderline condition was simply a subtle form or an exaggeration of something else. Clearly, a systematic approach to evaluating all of the accumulated knowledge about this condition was necessary if a clear diagnosis was to be obtained.

\section{Diagnosis of the Borderline}

Oddly enough, one of the breakthrough studies in systematic appraisal of the borderline state was simply a review of the literature. Gunderson and Singer (1975) synthesized information from eighty-seven borderlinerelated studies and extracted the consistencies therein. Addressing the behavior-affect-psychos is paradigm; six features that provided a rational meaning for diagnosis were identified: intense affect often of depressive or hostile nature, some abilities of social adaptability, background of impulsive behaviors, loose thinking in unstructured situations, brief psychotic experiences, and relationships vacillating between transient superficiality and intense dependency. Gunderson and 
Singer's other major finding (and message to future researchers) was that variances in accounts of the borderline patient frequently arose due to who was describing them, in what context, how the samples were selected, and what data were collected. Indeed, it did seem that studies in the aftermath of Gunderson and Singer achieved increasing commonality in describing the borderline traits, if not their conceptualization or source.

In developing the third edition of the Diagnostic and Statistical Manual (DSM III) of the American Psychiatric Association, a study was commissioned to investigate "borderline schizophrenia" and "borderline personality" -- currently the most commonly used terms in this realm. Spitzer, Endicott, and Gibbon (1978) in consultation with Gunderson, Kernberg, and others, developed nine criteria characteristic of borderline persons. Via questionnaire to practicing psychiatrists, 808 descriptions were obtained, all of which affirmed the nine criteria to be more frequently true of the borderline patient. Eight of these nine criteria were the definitive symptoms now included in DSM III; five of which must be met for conclusive diagnosis. In brief these criteria are impulsivity or unpredictability, a pattern of unstable or intense interpersonal relationships, marked shifts of attitude, inappropriate or intense anger, identity disturbance, affective instability, intolerance of being alone, physically self-damaging acts, and chronic feelings of emptiness or boredom.

Although the storm of controversy over Borderline has subsided with its inclusion in the DSM III, debate still continues in several areas. In authoritatively labeling the condition a "personality disorder," 
but indicating criteria that run the gamut of psychosis-neurosis/moodcharacter disordered symptomatology, it is as if DSM III playęd à trick on all of the single-minded theoreticians that went before. Subsequently, theoreticians have "turned about" and rediscovered a tool seldom used by them before DSM III's systematic rules of diagnosis were published: that of psychological testing.

\section{Psychological Testing of the Borderline}

Where the literature leading up to the consistent diagnos is of the borderline personality disorder is immense; that of psychological testing of the borderline is modest, even though peculiar Rorschach data first illuminated the possibility of such a disorder (Rorschach, 1921/1975). As clinicians debated the characteristics of these patients, psychometricians were developing their own set of criteria to signal a borderline state and were widely in agreement. The borderline patient was one who showed ordinary reasoning and communication in highly structured test situations such as the Wechsler Adult Intelligence Scale, but who on projective techniques such as the Rorschach, where structure is low, demonstrated flamboyantly deviant reasoning and thought processes (Singer, 1977). This very finding, however, imposed its own limitation on the range and methodology of testing research possible. Most studies involved projective tests, and because of the nature of administering such, also involved case reports. In addition, lacking clinical concurrence on the existence or characteristics of the borderline personality, a researcher in essence could only report results and speculate on causes. 
The establishment of standardized diagnostic criteria has now made it possible to use the diagnosis of Borderline Personality Disorder, when assigned in accordance with the DSM III, and thus study group performance on any type of testing instrument. Recent studies of borderline personality disorder MMPI test patterns are evidence that researchers are indeed moving in this new direction.

Snyder, Pitts, Goodpaster, Sajadi, and Gustin (1982) compared the MMPI profiles of 26 male inpatient Borderline Personality Disorders with 19 Dysthymic Disorders. Initial findings showed Borderlines scoring higher in Psychasthenia and Schizophrenia; but discriminant analysis indicated that the $L$ and $F$ validity scales of the MMPI were the best predictors of separation between the groups.

In a far more intensive analysis, Gustin, Goodpaster, Sajadi, LaBasse, Snyder, and Pitts (1983) compared the MMPI profiles of 29 male veteran inpatients diagnosed Borderline Personality with those of 26 patients diagnosed as other different personality disorders. The Borderline's profile was significantly more elevated on all of the scales than that of the other personality disorders but exhibited no pattern differences. Gustin et a1. conclude from these results that Borderlines are at a more extreme point on a severity continuum of personality disorders, but their qualitative symptom complex is not distinctly different.

Both of these studies are indicative of the new frontier opened in Borderline research. With groups reliably diagnosed using specified criteria, testing characteristics can be pinpointed and in turn, reapplied in the future to single out these disorders which require a specialized therapeutic approach. Concurrently, theoreticians can 
continue their debate as to what the borderline state does and does not resemble with the visible and measurable evidence of standardized test scores. 
CHAPTER II

PURPOSE OF STUDY

The purpose of this study was to investigate test performance of Borderline Personality Disorders on the Symptom Checklist (SCL-90; Derogatis, Rickels, \& Rock, 1976). The Symptom Checklist is a selfreport inventory which provides ratings on nine symptom dimensions and produces a profile-type configuration similar in appearance to that of the MMPI. The Symptom Checklist is popular in clinical settings because it is relatively unambiguous for the patient and takes only ten to twenty minutes to complete.

The patients in this study were participants in the Providence Hospital Day Treatment Program. These patients are characterized by a past history of psychiatric treatment and/or hospitalization. Day treatment is an effective therapeutic setting for psychiatric disorders needing considerable structure. Thus Providence serves a large number of Borderline Personality Disorders and Schizophrenic Disorders, as well as Affective Disorders and other personality disorders.

The design of this study is similar to the MMPI profile investigations reviewed in the introduction and addresses the following questions:

a) What is the characteristic symptom profile of Borderline Personality Disorders on the SCL-90?

b) Is this profile distinguishable from that of Schizophrenics and another comparison group comprised of Major Affective Disorders and other personality disorders? If so, which of 
the SCL-90 symptom dimensions account for the distinctions?

Results of this inquiry are examined in terms of the Borderline Personality's place in the spectrum of the comparison groups' disorders. Implications of these results for community mental health treatment are discussed. 
CHAPTER III

METHOD

Subjects

Subjects in this study were from the psychiatric outpatient population served by the Providence Hospital Day Treatment Program between Apri1, 1980 and September, 1982. These patients were both male and female. Ages range from approximately 18 to 70 years; the majority being in the 25-45 year range.

Sixty percent of the patients admitted to the program during this period were voluntary participants, having been referred by private mental health professionals. This study did not consider samples from the remaining "involuntary" participants who were court-mandated for treatment.

The investigator considered the population of all voluntary patients for sample inclusion. Subjects were excluded from sample inclusion for the following reasons:

a) Subject did not sign an informed consent for the SCL-90 to be used for research.

b) Subject did not completely finish the SCL-90 questionnaire upon admission.

c) In addition to subject's psychiatric diagnosis, there was a diagnosis of organic brain damage, epilepsy, or mental retardation.

d) Subject had a diagnosis of both Major Affective Disorder and Borderline Personality Disorder.

From a possible population of 150 subjects, 135 met the criteria 
for sample inclusion. Table I lists each group's characteristics with respect to age, sex, and prior hospitalizations.

\section{TABLE I}

SAMPLE CHARACTERISTICS

$$
\text { Male } \frac{\mathrm{N}}{\mathrm{Female}} \quad \begin{gathered}
\text { Age Range } \\
(\text { Mean })
\end{gathered}
$$

Prior Hospitalizations Range

(Mean)

$\begin{array}{lccc}\text { Borderlines } & 52 & 19-71 & 0-25 \\ & 10 / 42 & (40.5) & (2.9) \\ \text { Schizophrenics } & 40 & 19-47 & 0-7 \\ & 28 / 12 & (27.8) & (2.4) \\ \text { Other } & 43 & 21-76 & 1-10 \\ & 25 / 18 & (40.0) & (1.5)\end{array}$

Materials

The testing instrument used in this study is the Symptom Checklist (SCL-90; Derogatis, Rickels, \& Rock, 1976). The test consists of ninety symptom items which the subject answers as to how much distress each symptom has caused in the past week. Frequency ratings are done on a Likert scale basis from 0 to 4 indicating "not at all" to "extremely."

When scored, the SCL-90 produces I scores on nine symptom scales: Somatization, Obsessive-Compulsiveness, Interpersonal Sensitivity, Depression, Anxiety, Hostility, Phobic Anxiety, Paranoid Ideation, and Psychoticism. Only eighty-three of the test items are included in scoring symptom scales. The extra seven items question appetite and 
sleep patterns, morbid preoccupation and guilt level.

An additional three scales called "global indices" are derived from the number and intensity of symptoms the subject records experiencing. These are: 1) Global Severity Index - a combination of symptom count and symptom intensity; 2) Positive Symptom Distress Index - intensity of symptoms corrected for count resulting in a measure of exaggeration of or excess attention to symptoms; and 3) Positive Symptom Total - symptom count only.

\section{Procedure}

Subjects were administered the Symptom Checklist during the initial evaluation session upon admission to the Day Treatment Program. At that time subjects could elect to sign an informed consent for the SCL-90 test results to be used for research purposes. The SCL-90 was scored in accordance with Administration and Procedures Manual (Derogatis, 1977) by the program receptionist or coordinator and made a part of the subject's treatment file.

Subjects also underwent a three-hour personal interview with a staff professional during which demographic information and a psycho-social history were obtained. The results of this interview, together with records and consultation from the referring psychologist or psychiatrist, were considered in full staff conference to arrive at a diagnosis for the subject. The program staff consisted of one psychiatrist, one associate psychologist, three psychiatric social workers, two occupational therapists and one mental health therapist. Diagnoses were made in accordance with DSM I.II criteria. The SCL-90 test results were occasionally con- 
sulted in this process for treatment planning purposes only.

The investigator examined the treatment files for the subjects meeting this study's sample inclusion criteria and recorded the following information:

a) Age, sex, and number of prior hospitalizations.

b) Diagnosis.

c) The I scores for the nine symptom and three global scales on the SCL-90 test profile.

d) The Likert scores for the seven additional test items not included in the symptom scales.

Subjects were classified according to diagnosis for inclusion in one of three groups: 1) Borderline Personality Disorder; 2) Schizophrenic Disorder; 3) Other - this group consisting primarily of one-third Major Affective Disorder and two-thirds other personality disorders.

Data Analysis

All information recorded for each subject was keypunched onto IBM cards for analysis. Descriptive statistics for age, sex, and number of prior hospitalizations were obtained for each group. Two sets of dependent variables were considered in investigating the characteristics of the groups. The first set consisted of the subjects' scores on the nine symptom and three global scales of the SCL-90. The second set of variables were scores on each of the seven individual test items which are not included in deriving the symptom scales.

Since personality constructs underly all of the dependent variables, a discriminant analys is was employed to take into account correlation of 
certain factors in contributing to group differences. Box's $M$ was calculated for group dispersion in order to ascertain that homogeneity of variance assumptions necessary for the discriminant analyses were met.

The profile of mean scores on the twelve test scales for the Borderline Personality Disorder group were compared individually with those of the other two groups. The three groups were also examined together. In each case a stepwise discriminant procedure determined which test variables were the best predictors of group separation. Once the linear functions of predictor variables were derived, they were applied to examine the probability of each subject being reclassified into his correct group.

The seven test item scores were similarly analyzed. A discriminant analysis was employed to examine which of these variables predicted significant separation between the three groups, and a reclassification procedure was also performed.

Finally, all nineteen test variables were subjected to a discriminant analysis to determine if any of the seven test item scores were more effective in separating the three groups than any of the twelve scales. 


\section{CHAPTER IV}

\section{RESULTS}

\section{Central Tendencies and Discriminant Analyses}

Means and standard deviations for each group's scores on the SCL-90 symptom and global scales are presented in Table II. The resultant test profiles in Figure 1 illustrate that the Borderline group is more highly elevated on ten of the twelve scales than the other two groups. To determine whether this elevation was significant, Hoteling's $I^{2}$ procedure was used to test whether the groups differed when the twelve variables were considered simultaneously. Results indicated that the Borderline

TABLE II

MEANS AND STANDARD DEVIATIONS OF SCL-90 SCALES

\begin{tabular}{|c|c|c|c|}
\hline & $\begin{array}{l}\text { Borderline } \\
\text { Mean } \\
\text { (SD) }\end{array}$ & $\begin{array}{c}\text { Schizophrenics } \\
\text { Mean } \\
\text { (SD) }\end{array}$ & $\begin{array}{l}\text { Other } \\
\text { Mean } \\
\text { (SD) }\end{array}$ \\
\hline 1. Somatization & $\begin{array}{l}51.9 \\
(10.4)\end{array}$ & $\begin{array}{l}48.3 \\
(8.8)\end{array}$ & $\begin{array}{l}48.9 \\
(9.6)\end{array}$ \\
\hline 2. Obsessive-Compulsive & $\begin{array}{l}52.1 \\
(10.1)\end{array}$ & $\begin{array}{l}50.4 \\
(8.9)\end{array}$ & $\begin{array}{l}48.9 \\
(8.7)\end{array}$ \\
\hline $\begin{array}{l}\text { 3. Interpersonal } \\
\text { Sensitivity }\end{array}$ & $\begin{array}{l}52.4 \\
(9.7)\end{array}$ & $\begin{array}{c}48.9 \\
(11.4)\end{array}$ & $\begin{array}{l}46.8 \\
(9.9)\end{array}$ \\
\hline 4. Depression & $\begin{array}{l}52.9 \\
(11.9)\end{array}$ & $\begin{array}{l}46.8 \\
(10.6)\end{array}$ & $\begin{array}{l}47.3 \\
(9.9)\end{array}$ \\
\hline
\end{tabular}


TABLE II (continued)

MEANS AND STANDARD DEVIATIONS ON SCL-90 SCALES

$\begin{array}{ccc}\text { Borderline } & \text { Schizophrenic } & \text { Other } \\ \text { Mean } & \text { Mean } & \text { Mean } \\ \text { (SD) } & \text { (SD) } & \text { (SD) }\end{array}$

$\begin{array}{lccc}\text { 5. Anxiety } & 52.2 & 47.4 & 45.8 \\ & (12.7) & (10.3) & (9.7)\end{array}$
6. Hostility
48.9
44.1
48.3
(10.2)
(10.8)
(10.9)
7. Phobic Anxiety
54.7
52.6
$(9.7)$
48.1
(11.3)
8. Paranoid Ideation
51.0
(9.6)
51.8
(10.4)
48.9
(10.0)

9. Psychoticism

50.9
$(10.7)$

51.2

(13.6)

45.9

(9.4)

\begin{tabular}{|c|c|c|c|}
\hline 10. GSI & $\begin{array}{c}51.8 \\
(11.7)\end{array}$ & $\begin{array}{c}48.1 \\
(11.3)\end{array}$ & $\begin{array}{r}47.0 \\
9.1)\end{array}$ \\
\hline
\end{tabular}

11. PSDI

52.4

(13.5)

49.5

47.9

(10.5)

(10.6)

12. PSI

52.5

(11.2)

48.2

47.4

(11.8)

(9.7) 


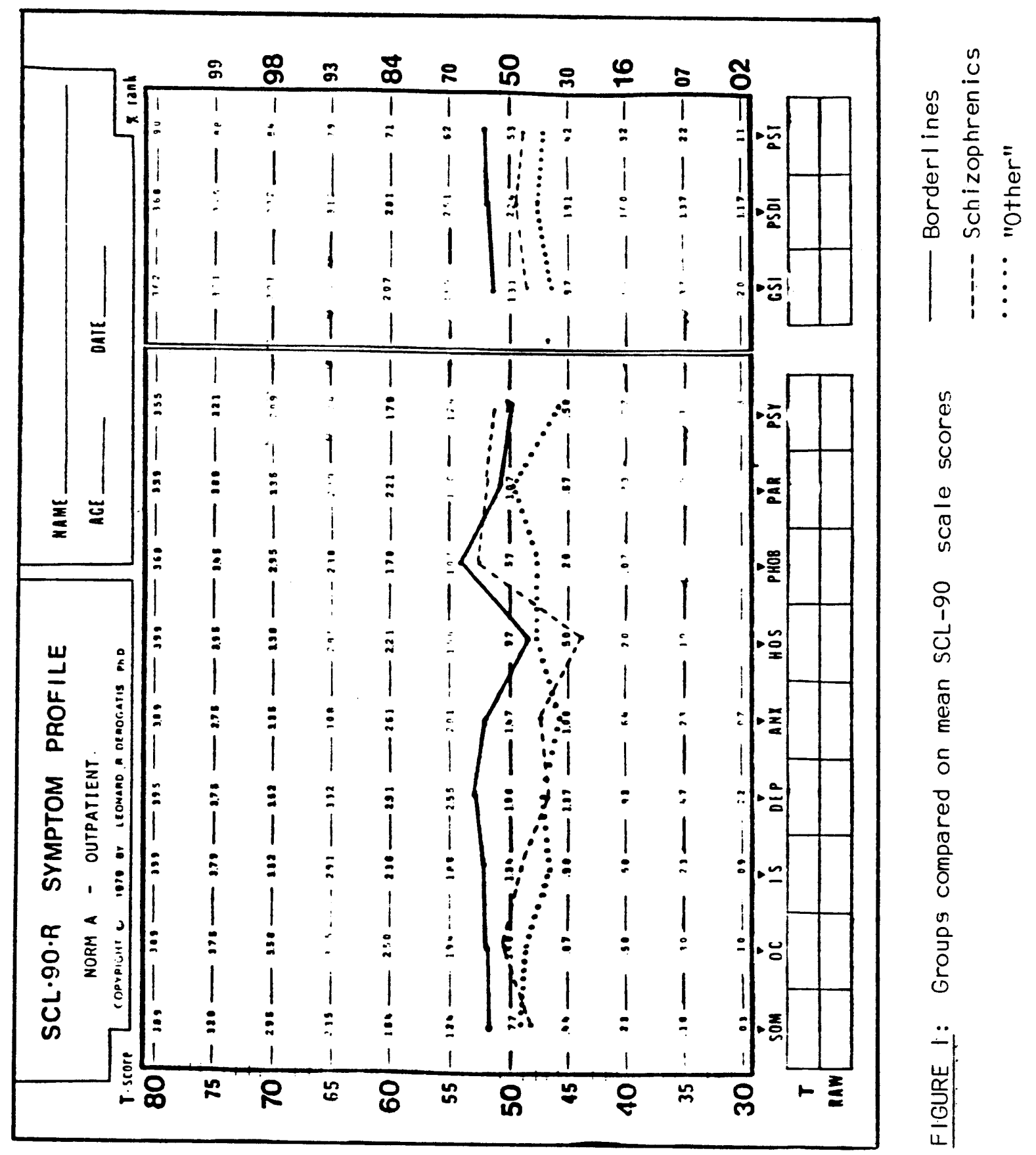


group is significantly different from both the Schizophrenic group, $\underline{F}(12,79)=3.37, \underline{p}(.01$, and the "Other" group, $\underline{F}(12,82)=5.32$, $p<.01$. Interpreted univariately, the Borderline group is significantly elevated over the other two groups on symptom and global test scales.

Since the Borderline group is of particular interest to this study, it was examined further for sex differences on the symptom-scale means The profile for the ten male Borderlines imitated the females in direction of elevation but was more extreme on the dimensions of Depression, Anxiety, Phobic Anxiety, and Psychoticism, as is exhibited in Table III.

TABLE III

MALE/FEMALE BORDERLINE MEANS COMPARISON

\begin{tabular}{|c|c|c|c|c|}
\hline Symptom Scale & Males & $t$-test & Females & Group \\
\hline Depression & 57.1 & $\underline{t}=.45 p>.5$ & 51.8 & 52.9 \\
\hline Anxiety & 56.3 & $t=.42 p>.5$ & 51.2 & 52.2 \\
\hline Phobic Anxiety & 58.2 & $\underline{t}=.39 \mathrm{p} 7.5$ & 53.8 & 54.7 \\
\hline Psychoticism & 56.4 & $\underline{t}=.65 p>.5$ & 49.6 & 50.9 \\
\hline
\end{tabular}

These differences can only be considered suggestive rather than definitive due to the small sample size of the males and the statistical insignificance of the results.

Table III summarizes the Box's M statistics used to evaluate whether there was significantly greater dispersion about the profiles for any of the groups. Results indicated that the groups are not differ- 
TABLE IV

RESULTS OF BOX'S M TEST OF COVARIANCE MATRICES

Comparison Box's $\underline{M}$ Approximate $\underline{F}$ Degrees of Freedom Significance

Borderline/

Schizophrenic

9.50

1.52

$(6,49056)$

p).16

Borderline/

"Other"

12.41

1.99

$(6,56866)$

p) .06

\section{All three} groups

23.98

1.14

$(20,57048)$

p) .29

entially variable, and the null hypothesis of homogeneity of variance can be upheld.

Given the confirmation of homogeneity of variance, test profile comparison was performed by using the Discriminant Analysis program in the Statistical Package for the Social Sciences (Nie, Hull, Jenkins, Steinbrenner, \& Bent, 1975). At each step of this analys is the program looks at all of the variables together and chooses the one that accounts for the greatest amount of variability between the groups (" $\underline{F}$ to enter"). This procedure is performed anew each time, since correlation among variables may mask a heavily weighted predictor until a more highly correlated variable is removed from consideration.

In comparing the Borderline group with the Schizophrenic group, the variables of Depression, Psychoticism, and Positive Symptom Total were found to be the best predictors for between-groups variance. In the first step, the $\underline{F}$ to enter Depression was $6.37(1,90)$ while that of 


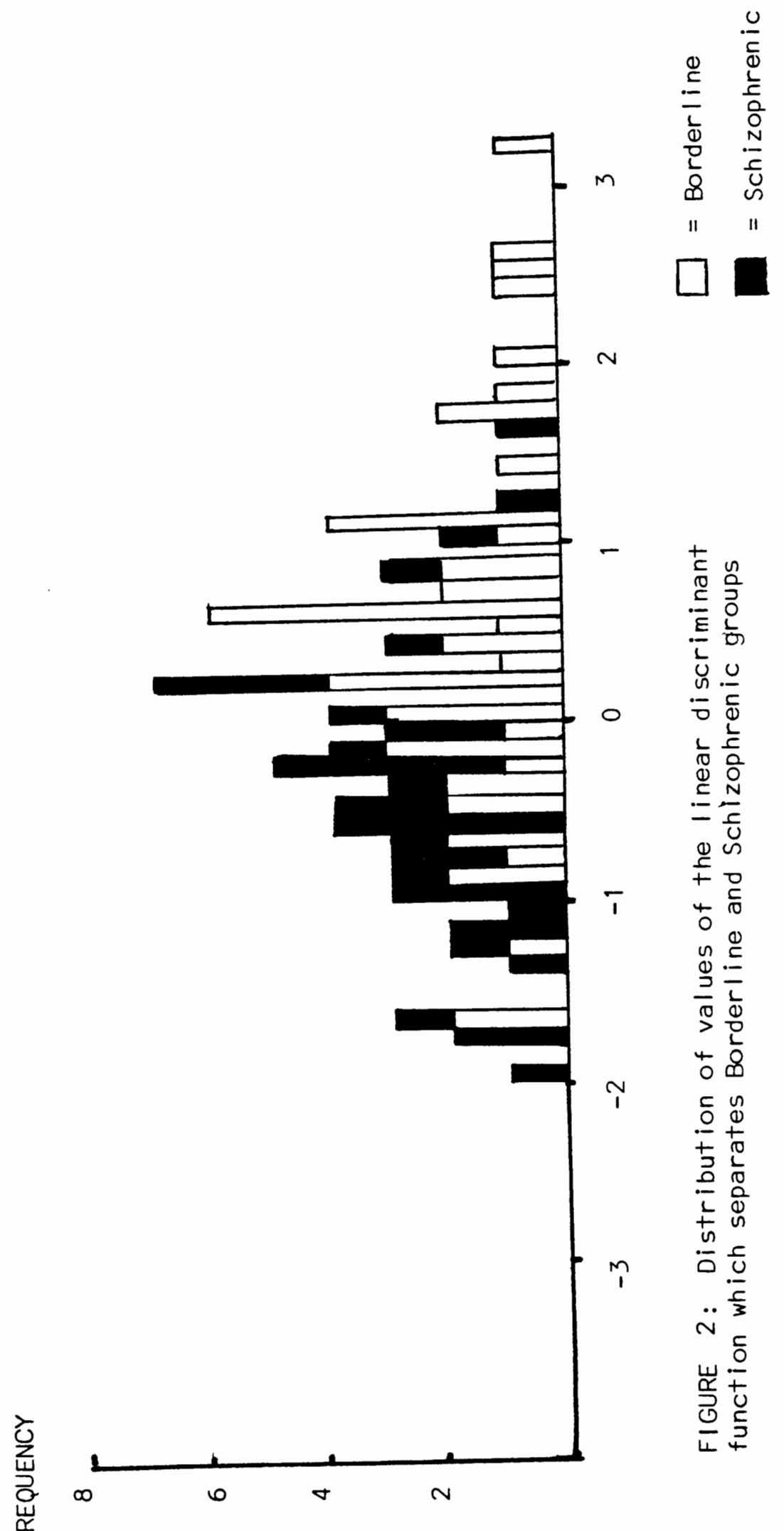


Psychoticism was a miniscule $.0093(1,90)$. However, once Depression was taken out of consideration, accounting for $7 \%$ of the variance between groups, Psychoticism became the next best predictor, with $\underline{F}$ to enter of $10.04(1,89)$ accounting for another $9 \%$ of the variance. Likewise, the variable of Positive Symptom Total had an $\underline{E}$ to enter of $.0019(1,89)$ after step 1 but arose as the best predictor $(\underline{F}(1,88)=4.52)$ after Psychoticism was removed, accounting for an additional $5 \%$ of between group variance. At this point the remaining variables were insignificant $(\underline{F}(1,87)=2.5, p\rangle .05)$ in accounting for further group variance, and the stepwise analysis was stopped.

\section{TABLE V}

SUMMARY OF DISCRIMINANT ANALYSIS BORDERLINES/SCHIZOPHRENICS Variable Standardized Linear Discriminant Wilks' Lambda Function Coefficient

Depression

1.19

.93

Psychoticism

$-1.68$

.84

Positive Symptom Total

.89

Table $V$ summarizes the comparison of the Borderline group with the Schizophrenic group. Large positive coefficients on the variables of Depression and Positive Sumptom Total indicate separation -- the Borderlines: scores are significantly different (higher) on these scales. The large negative coefficient for the Psychoticism variable in the discriminant function indicates similarity between the groups on this 


\section{TABLE VI}

CLASSIFICATION ON BASIS OF

BORDERLINES/SCHIZOPHRENICS DISCRIMINANT FUNCTION

Predicted Group Membership

$\begin{array}{llll}\text { Actual } & \text { No. of } & \text { Borderlines } & \text { Schizophrenics } \\ \text { Group } & \text { Cases } & & \end{array}$

Borderlines

52

35

$(67.3 \%)$

17

$(32.7 \%)$

Schizophrenics

40

10

$(25.0 \%)$

30

$(75.0 \%)$

scale. Wilks lambda shows that $21 \%$ of the between-groups variance can be accounted for by this function alone. This is significant at $\underline{p}=.0002, \underline{F}(3,88)=7.42$.

The subjects' scores on SCL-90 scales were reevaluated with this discriminant function to see if they would be classified in the correct group. Figure 2 illustrates the distribution of subjects' values on the discriminant function. As is shown in Table VI, 67\% of the Borderlines and $75 \%$ of the Schizophrenics can be correctly classified for this sample.

A second discriminant analysis compared the Borderline group with the "Other" group. The variables of Phobic Anxiety and Hostility were found to be the best predictors for variance between these groups. In the first step the $E$ to enter Phobic Anxiety was $10.02(1,93)$ while Hostility was a low .072 $(1,93)$. However, once Phobic Anxiety was removed accounting for $10 \%$ of between-groups variance, the $\underline{F}$ to enter Hostility rose to $1.06(1,92)$, accounting for another $1 \%$ of the variance. 
TABLE VII

SUMMARY OF DISCRIMINANT ANALYSIS BORDERLINES/"OTHERS"

Variable

Standardized Linear Discriminant

Function Coefficient

Phobic Anxiety

1.08

.90

Hostility

$-.35$

.89

Table VII summarizes the comparison of the Borderline group with the "Other" group. A large positive coefficient on the variable of Phobic Anxiety indicates separation between the groups -- Borderlines score significantly higher on this scale than "Others." The negative Hostility coefficient shows that similarity on this scale is the next best predictor in the function accounting for group variances. By comparing the coefficients of this function with those of Table $V$ 's function discriminating Borderlines from Schizophrenics, it can be seen that the absolute magnitude of the weighted predictors are not as large. Wilk's 1 ambda indicates that this function can account for $11 \%$ of the variance between the Borderline and "Other" groups. This is significant at $\underline{p}=.005, \underline{F}(2,92)=5.54$.

As in the first discriminant analysis, the subjects' scale scores for the Borderline and "Other" group were evaluated with this resultant discriminant function to examine the likelihood of correct group classification. Figure 3 illustrates the distribution of the subjects' values on the discriminant function. As is seen in Table VIII this function predicts the correct classification of the Borderlines $51.9 \%$ of the time, 


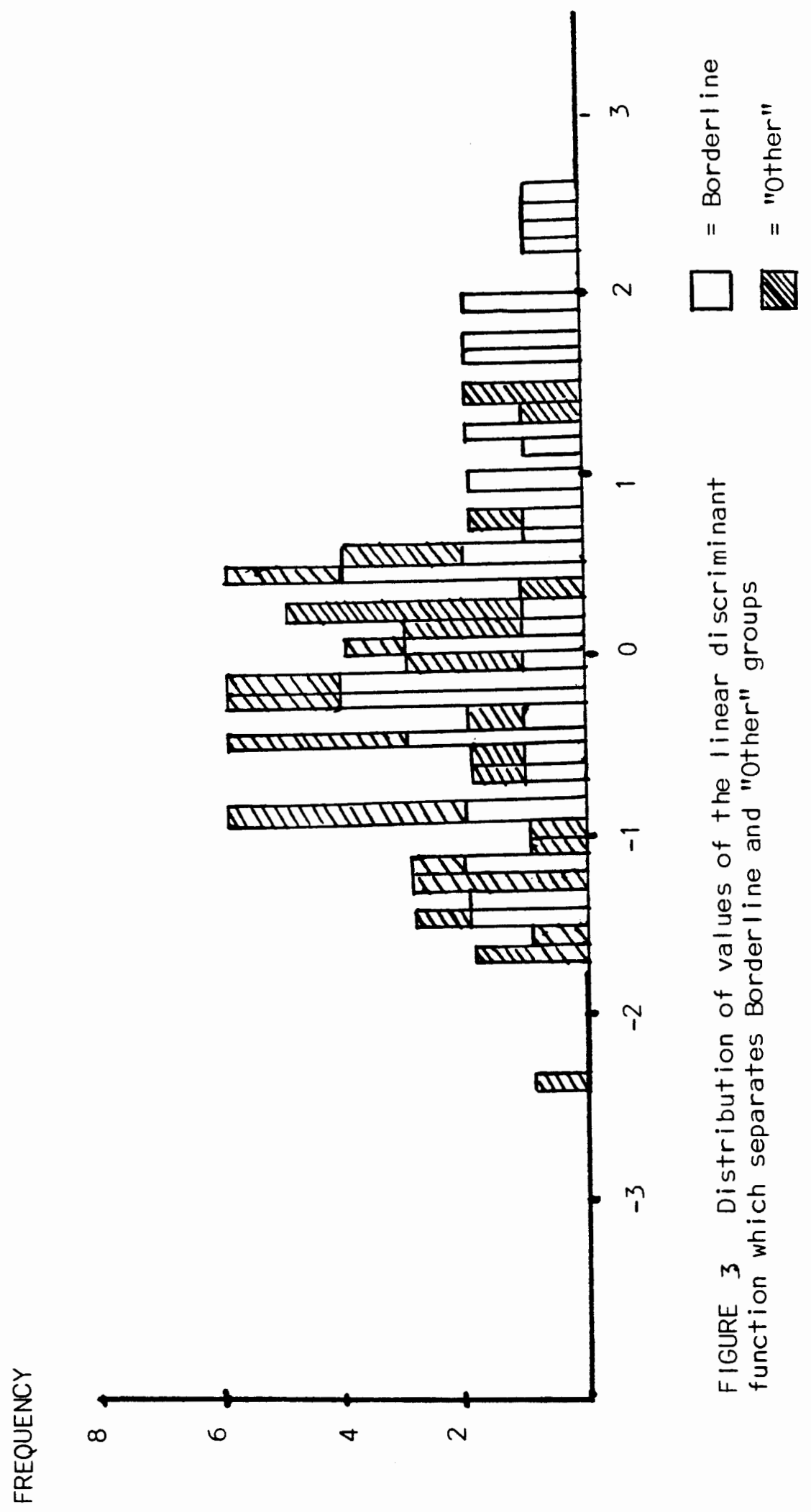




\section{TABLE VIII}

CLASSIFICATION ON BASIS OF

BORDERLINE/OTHER DISCRIMINANT FUNCTION

\begin{tabular}{lccc}
\hline $\begin{array}{l}\text { Actual } \\
\text { Group }\end{array}$ & $\begin{array}{l}\text { No. of } \\
\text { Cases }\end{array}$ & $\begin{array}{c}\text { Predicted Group Membership } \\
\text { Borderlines }\end{array}$ & Other \\
\hline Borderlines & 52 & 27 & 25 \\
& & $(51.9 \%)$ & $(48.1 \%)$ \\
Other & 43 & 16 & 27 \\
\hline
\end{tabular}

and the "Other" group $62.8 \%$ of the time for this sample. Clearly, the function discriminating Borderlines from the "Other" group is not as effective a predictor as the function discriminating the Borderlines from Schizophrenics.

The third discriminant analys is was performed on all three groups together. Three of the five variables which were found to be significant predictors in the two-group comparisons were also found to be significant predictors in the accounting for variance in the three-group comparison. These were Phobic Anxiety, Hostility, and Depression. The variable of Paranoid Ideation was also found to be a predictor. Two linear discriminant functions were necessary to describe the differences in variance among the groups and Table IX summarizes these results.

When these two functions derived in the three-group analys is are taken together they define a three-dimensional space accounting for $22 \%$ of group variance. Function I defines $65 \%$ of this variance and Function II defines $35 \%$. Thus, Function I's parameters giving weight to separa- 
TABLE IX

SUMMARY OF DISCRIMINANT ANALYSIS ALL THREE GROUPS

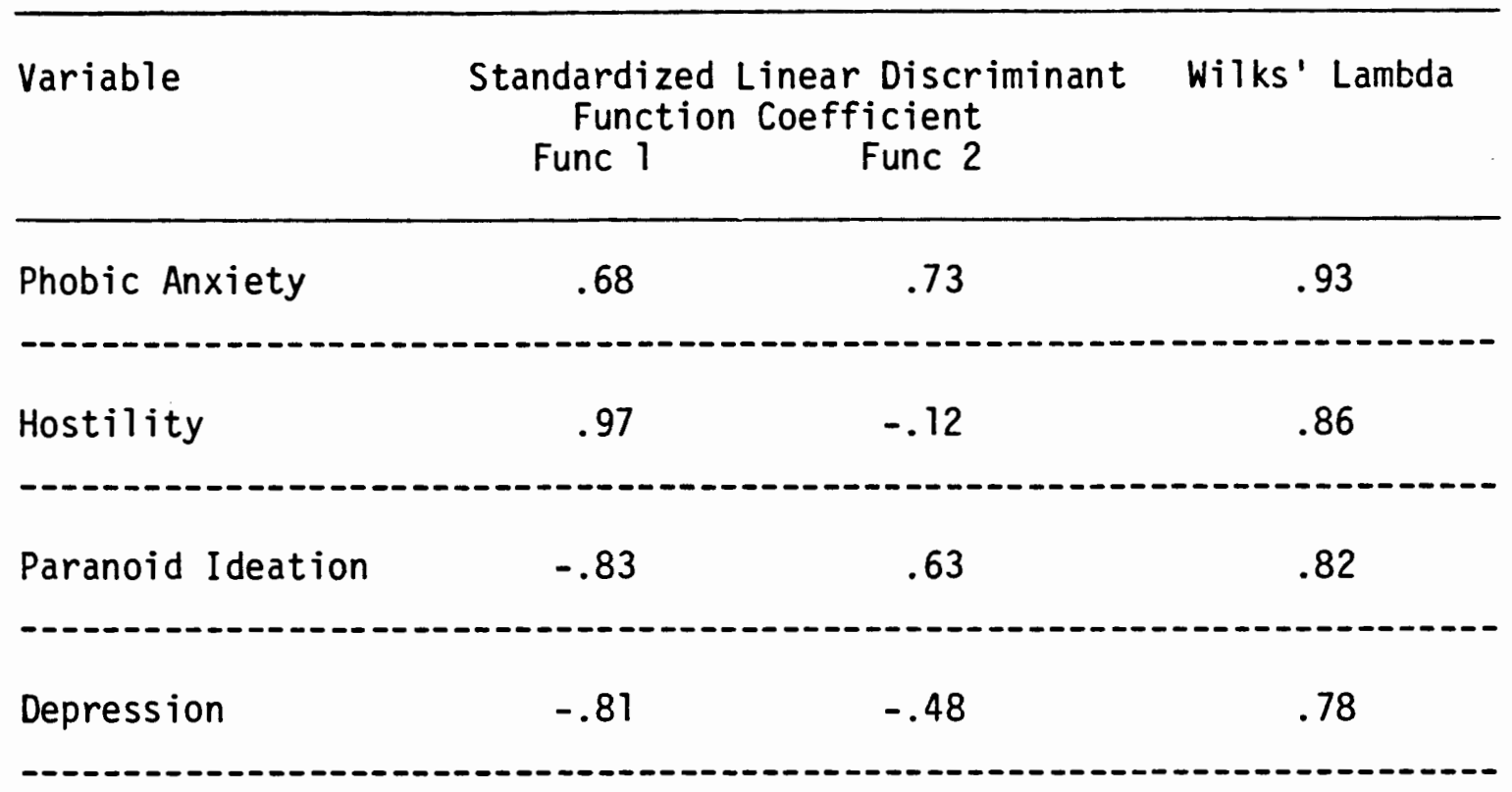

tion on the Phobic Anxiety and Hostility scales and similarity on the Paranoid Ideation and Depression scales can be seen to contribute approximately twice as much information about group variances as that of Function II. This function shows separation on the Paranoid Ideation scales as well as the Phobic Anxiety scales and similarity on Hostility and Depression. The fact that two separate discriminant functions are significant in accounting for group variance and that the absolute magnitude of the weighted coefficients on each function are not particularly large, indicates that discrimination of the three groups taken together will not be as effective as the two-group comparisons. Indeed, the reclassification results presented in Table $X$ bear this out.

When subjects' scores on the SCL-90 symptom and global scales were reevaluated using both of these discriminant functions, the probability of the Schizophrenics and "Others" being classified in the correct 
TABLE $X$

CLASSIFICATION ON BASIS OF

BORDERLINE/SCHIZOPHRENIC/OTHER DISCRIMINANT FUNCTIONS

Predicted Group Membership

Actual Group

No. of

Borderlines

Schizophrenics Other

Cases

\begin{tabular}{|c|c|c|c|c|}
\hline Borderlines & 52 & $\begin{array}{c}22 \\
(42.3 \%)\end{array}$ & $\begin{array}{c}14 \\
(26.9 \%)\end{array}$ & $\begin{array}{c}16 \\
(30.8 \%)\end{array}$ \\
\hline Schizophrenics & 40 & $\begin{array}{c}10 \\
(25.0 \%)\end{array}$ & $\begin{array}{c}24 \\
(60.0 \%)\end{array}$ & $\begin{array}{c}6 \\
(15.0 \%)\end{array}$ \\
\hline Other & 43 & $\begin{array}{c}10 \\
(23.3 \%)\end{array}$ & $\begin{array}{c}9 \\
(20.9 \%)\end{array}$ & $\begin{array}{c}24 \\
(55.8 \%)\end{array}$ \\
\hline
\end{tabular}

group was only $60 \%$ and $56 \%$ respectively. Furthermore, only $42 \%$ of the Borderlines could be reclassified into the ir correct group.

Overall, the discriminant analyses of SCL-90 profiles produced the best results in depicting separation of the Borderline group from the Schizophrenic group according to weighted predictor functions. Borderlines were less likely to be classified correctly by their predictors in comparison to the "Other" group, and even less likely when competing with both groups together.

Continuing to investigate group differences on the SCL-90, the seven additional test items were next examined. Table XI presents the mean scores and standard deviations of these items for each of these groups. This score is based on a Likert scale of 0 to 4 . Box's $\underline{M}$ was calculated for a three-group comparison yielding a value of 23.2 $(\underline{F}(12,76185)=1.8, \underline{p}=.03)$. Results indicated that the three 
TABLE XI

MEANS AND STANDARD DEVIATIONS FOR SEVEN TEST ITEMS

\begin{tabular}{|c|c|c|c|}
\hline & $\begin{array}{c}\text { Borderline } \\
\text { Mean } \\
\text { ( } \underline{S} \underline{D})\end{array}$ & $\begin{array}{c}\text { Schizophrenic } \\
\text { Mean } \\
(\underline{S D})\end{array}$ & $\begin{array}{l}\text { Other } \\
\text { Mean } \\
(\underline{S} \underline{D})\end{array}$ \\
\hline Poor Appetite & $\begin{array}{c}1.2 \\
(1.4)\end{array}$ & $\left(\begin{array}{c}.4 \\
(1.0)\end{array}\right.$ & $\begin{array}{l}.5 \\
(.8)\end{array}$ \\
\hline Overeating & $\begin{array}{l}1.0 \\
(1.5)\end{array}$ & $\left(\begin{array}{c}.8 \\
(1.3)\end{array}\right.$ & $\begin{array}{l}1.1 \\
(1.5)\end{array}$ \\
\hline Trouble Falling Asleep & $\begin{array}{l}1.7 \\
(1.4)\end{array}$ & $\begin{array}{l}1.1 \\
(1.3)\end{array}$ & $\begin{array}{l}1.3 \\
(1.5)\end{array}$ \\
\hline $\begin{array}{l}\text { Awakening in Early } \\
\text { Morning }\end{array}$ & $\begin{array}{l}1.6 \\
(1.5)\end{array}$ & $\begin{array}{l}1.3 \\
(1.4)\end{array}$ & $\begin{array}{l}1.3 \\
(1.5)\end{array}$ \\
\hline $\begin{array}{l}\text { Restless or Disturbed } \\
\text { Sleep }\end{array}$ & $\begin{array}{l}1.7 \\
(1.4)\end{array}$ & $(1.8)$ & $\begin{array}{l}1.3 \\
(1.4)\end{array}$ \\
\hline $\begin{array}{l}\text { Thoughts of Death or } \\
\text { Dying }\end{array}$ & $\begin{array}{l}1.6 \\
(1.5)\end{array}$ & $(1.2)$ & $(1.9)$ \\
\hline Feelings of Guilt & $\begin{array}{c}2.5 \\
(1.3)\end{array}$ & $\begin{array}{l}1.2 \\
(1.4)\end{array}$ & $\begin{array}{l}1.1 \\
(1.2)\end{array}$ \\
\hline
\end{tabular}

groups may be differentially variable. Hays (1973) states, however, that where a difference in means and roughly equal sample sizes exist, analyses of variances can and should be performed. Thus, the seven test items were analyzed using the same stepwise procedues as the preceding scale analyses.

In a three-group comparison only one discriminant function con- 
TABLE XII

CLASSIFICATION ON BASIS OF

TEST ITEMS DISCRIMINANT FUNCTIONS

Predicted Group Membership

Actual

Group

No. of

Borderlines

Schizophrenics Other

Cases

Borderlines $\quad 52 \quad(69.2 \%) \quad(19.2 \%) \quad(11.5 \%)$

Schizophrenics

40

11

$(27.5 \%)$

22

$(55.0 \%)$

7

$(17.5 \%)$

other

43

10

$(23.3 \%)$

15

$(34.9 \%)$

18

$(41.9 \%)$

taining one predictor variable was significant. This variable, "Feelings of Guilt," accounted for $21 \%$ (Wilks' lambda $=.79)$ of the variance between groups. The weighted standardized function coefficient was .95 , Borderlines scoring relatively high compared to Schizophrenics and "Others." The second best predictor of the seven test items was "Restless or Disturbed Sleep," but this variable was below statistical significance to enter the equation $(\underline{F}(1,132)=2.51, p) .05)$. Table XII shows reclassification results for the discriminant function containing the one predictor variable of guilt.

In interpreting the results of this specific analys is it must be remembered that scores indicated distress measured on a Likert scale representing:

$$
\begin{aligned}
& 0=\text { Not at all } \\
& 1=\text { A little bit }
\end{aligned}
$$




$$
\begin{aligned}
& 2=\text { Moderately } \\
& 3=\text { Quite a bit } \\
& 4=\text { Extremely }
\end{aligned}
$$

Means for the three groups on the guilt item range from 2.5 to 1.1; i.e., "mid-moderately" to "low-little bit." Thus, results may be only suggestive rather than definitive.

A final discriminant analysis examined the SCL-90 symptom and global scale variables and the seven non-scale test $i$ tems for the three groups together. In a three-group comparison two discriminant functions were derived to best predict group differences. Of all the nineteen test variables the best predictor of group variance was the test item of "Feelings of Guilt," accounting for $11 \%$ (Wilks' lambda $=.79)$. Of the remaining variables, the next best predictors were the Psychoticism scale score accounting for an additional 5\% (Wilks' lambda $=.74$ ) of the variance, and the Hostility scale score, accounting for $7 \%$ more of the variance $($ Wilks' lambda $=.67)$. At this point, the remaining variables were insignificant $(\underline{F}(2,258)=2.23, \underline{p}>.05)$ and were not entered into the analysis.

Table XIII shows the results of reclassifying the subjects into groups based on the discriminant functions of this analysis. Borderlines were reclassified correctly $69 \%$ of the time, Schizophrenics $50 \%$ of the time, and the "Other" group 56\% of the time. In comparing these reclassification results with those using the discriminant functions of the previous two-and three-group comparisons of symptom and global scale scores, it can be seen that the functions derived from this discriminant analysis with the test item of "Feelings of Guilt" weighted as the best predictor produce equal or better reclassification results. 
TABLE XIII

CLASSIFICATION ON BASIS OF

NINETEEN VARIABLE DISCRIMINANT FUNCTIONS

\begin{tabular}{|c|c|c|c|c|}
\hline \multirow[b]{2}{*}{$\begin{array}{l}\text { Actual } \\
\text { Group }\end{array}$} & \multirow[b]{2}{*}{$\begin{array}{l}\text { No. of } \\
\text { Cases }\end{array}$} & \multicolumn{3}{|c|}{ Predicted Group Menbership } \\
\hline & & Borderlines & Schizophrenics & Other \\
\hline Borderlines & 52 & $\begin{array}{c}35 \\
(67.3 \%)\end{array}$ & $\begin{array}{c}6 \\
(11.5 \%)\end{array}$ & $\begin{array}{c}11 \\
(21.2 \%)\end{array}$ \\
\hline Schizophrenics & 40 & $\begin{array}{c}8 \\
(20.0 \%)\end{array}$ & $\begin{array}{c}20 \\
(50.0 \%)\end{array}$ & $\begin{array}{c}12 \\
(30.0 \%)\end{array}$ \\
\hline other & 43 & $\begin{array}{c}10 \\
(23.3 \%)\end{array}$ & $(20.9 \%)$ & $\begin{array}{c}24 \\
(55.8 \%)\end{array}$ \\
\hline
\end{tabular}

Summary

SCL-90 test results were compared for 52 Borderline Personality Disorders, 40 Schizophrenics, and 43 Major Affective/other personality disorders. Means and standard deviations were calculated for all groups. The Borderline Personality Disorders group's test score profile was significantly elevated over the Schizophrenic and Major Affective/ other personality disorder group profiles. Means for male and female subjects in the Borderline Personality Disorder group were examined and male subjects were nonsignificantly higher on the symptom scale dimensions of Depression, Anxiety, Phobic Anxiety, and Psychoticism.

Discriminant Analysis was utilized to investigate which SCL-90 symptom and global scale scores would best predict group variances. In a two-group comparison between the Borderline and Schizophrenic groups, the best predictors were 1) separation on the Depression scale, 2). 
similarity on the Psychoticism scale, and 3) separation on the Positive Symptom Total scale. In a two-group comparison between the Borderline and Major Affective/other personality disorder groups, the best predictors were 1) separation on the Phobic Anxiety scale, and 2) similarity on the Hostility scale. In a three-group comparison between all the groups, the best predictors of group variance in weighted order were 1) Phobic Anxiety, 2) Hostility, 3) Paranoid Ideation, and 4) Depression.

The seven non-scale test items were subjected to Discriminant Analysis for comparison of the three groups. Only one test item, "Feelings of guilt," significantly accounted for group variance.

The twelve SCL-90 symptom and global scales and the seven nonscale test items were subjected to Discriminant Analysis together for the three groups. The best predictors of group variance in weighted order were 1) "Feelings of Guilt" test item, 2) Psychoticism scale, and 3) Hostility scale.

For all comparisons, the discriminant functions derived from the Discriminant Analysis were reapplied to subjects' test scores to examine the probability of subjects being reclassified into the correct group. For the Borderline vs. Schizophrenic group comparison, $67 \%$ of the Borderlines were reclassified correctly. For the Borderline vs. Major Affective/other personality disorder comparison, $52 \%$ of the Borderlines were reclassified correctly. In the three group comparison, only $42 \%$ of the Borderlines could be reclassified correctly. The discriminant function derived from comparison of the three groups on the seven non-scale test items, reclassified $69 \%$ of the Borderlines correctly. When the three groups were compared over the twelve SCL-90 symptom and global scales and seven non-scale test items together, the discriminant 


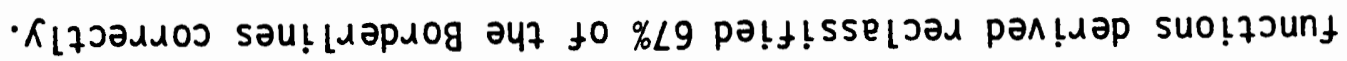




\section{CHAPTER $V$}

\section{DISCUSSION}

\section{Findings}

The purpose of this study has been to investigate test performance of the Borderline Personality Disorder on the Symptom Checklist. The results of this study show that the symptom profile is distinguishable from that of the comparison groups in elevation as well as pattern. This elevation indicates that the Borderline patient attests to a greater number and intensity of symptoms and does so over a wide variety of symptom dimensions. If the elevation of the profile is thought of in terms of the severity of distress, Borderlines rank slightly higher than Schizophrenics and are clearly distinct from the Major Affective/other personality disordered group.

This finding is in concurrence with the Gustin et al. (1983) MMPI study which found Borderline profiles to be significantly elevated over a comparison group of other personality disorders. The pattern of MMPI profiles however was similar, causing Gustin to conclude that Borderlines were much like other personality disorders but more severe. This present study presents distinct pattern differences between the Borderlines' profiles and those of comparison groups. This difference is most probably due to the SCL-90 being normed on psychiatric patients only. Thus, results of this study may be better able to distinguish the categories of disordered patients from each other than when the population as a whole is used as the baseline.

The DSM III diagnostic criteria can seem to the non-clinician as a 
hodgepodge of behavioral observations, wherein if the patient manages to exhibit the specified number of symptomatic behaviors, he can then be relegated to the borderline category. Given the assumption of diagnosis in accordance with these criteria, however, tests such as the MMPI and SCL-90 begin to illuminate the stable personality traits which underlie the behaviors of Borderlines. Theoreticians have focused on different attributes of these traits presenting a picture ranging over the full psychotic-neurotic/mood-character disordered arena. Therefore, one of the contributions that psychological testing can make is to continue to gather information as to where Borderlines can be placed in this psychiatric arena.

The results of this study cannot particularly address the mood versus character issue since Borderlines were compared to Major Affective Disorders and other personality disorders as one lumped group; this group being weighted predominantly in favor of the personality disorders but affected by possible organogenic affectivity. This comparison however, and that of Borderlines versus Schizophrenics, can be examined in light of the psychotic-neurotic continuum, particularly from a psychostructural viewpoint.

Schizophrenia is always delegated to the psychotic end of the continuum. When Borderlines were compared with this group, the second best predictor in distinguishing Borderlines was the correlation of both groups' high scores on the Psychoticism scale. This finding is complementary to the clinical studies of hospitalized borderline patients reporting psychotic episodes, and to results of projective testing recording the odd associations usually encountered in schizophrenia. The best predictor in distinguishing the Borderline group from the Schizophrenics 
overall, however, is the marked separation on the Depression scale; Borderlines being quite high, Schizophrenics low. Depression is a more neurotic defense mechanism in that it requires higher self-individuation. Where Schizophrenics seldom come out of a world of self, Borderlines care intensely about the world and objects (often persons) therein. Unmet needs by this world of objects are responded to in part by feelings of abandonment and despair.

Personality disorders are seen as falling at a midpoint on the psychotic-neurotic continuum. Here, defenses have developed over a long period of time into a characterologic pattern. When SCL-90 test results for Borderline Personality Disorders are compared with the Major Affective/other personality disorder group the second best predictor which distinguishes the groups is their similarity on the Hostility dimension. Rage is also a neurotic defense mechanism requiring selfindividuation and caring about the world. Where rage is a projection outward of the experience of unmet needs, depression is a turn inward. The depression scores of Borderline Personality Disorders are significantly higher than this other group which, taken together with rage, represents conflict. Significantly, the best predictor of separation between the two groups is the Borderlines' high score on Phobic Anxiety. A phobia is the essence of conflict; e.g., the wanting to be in the crowd and the fear of the crowd. Phobias actually help to bind the Borderlines' anxiety by narrowing their world and al lowing them to avoid certain stressors.

An important distinction can be carefully extracted from these twogroup comparisons taken holistically. "Psychotic" must be thought of as a descriptor rather than the mental illness itself. Where the Borderlines 
and Schizophrenics are similar in their psychoticism, Schizophrenics show less evidence of those traits requiring higher self-individuation. At the same time, Borderlines are strong in these neurotic manifestations, the pattern of which when compared to other personality disorders suggests primative conflict. These results fit in very well with the clinicalstructural model of schizophrenia being an organogenic as well as psychogenic $i 1$ lness rooted in loose thought association, thus stunting individuation into the outer world and producing delusional misperceptions. The Borderline, on the other hand, has seen the world but has not separated its meaning from himself, thus producing conflicting misperceptions about his own boundaries which can sometimes become delusional.

It is interesting that this study found the single test item of "Feelings of Guilt" to be the overall best predictor of Borderlines separation from the other groups, since guilt can be seen as an underlying theme, holding the borderline system together. Object-relations theorists present the infantile borderline dilemma as a deficit in being able to distance the experience of unmet needs from the "object" away from the self. Kernberg's "all-good/all-bad" splitting reaction, therefore, is also an experience of the self being all good or all bad depending on how needs are met by the object (or person or situation) at hand. The Borderline person with unmet needs reacts with rage and yet this rage must also be turned inward. Thus, for the Borderline person, life is a continuous cycle of desperate wanting, unmet needs perceived as abandonment, rage, and then guilt for the rage and the inability to be independent -- bringing on desperate need again. This is an emotional position of self-deingration and self-punishment which can bring on equally selfdamaging acts. 
Implications

Borderline Personality Disorders pose distinctive problems in the sphere of community mental health. One problem is simply that they may not be identified correctly and, if so, may not be taken seriously. Currently society's conmitment to mental illness is to prevent the expensive ordeal of hospitalization and custodial care. Bizarrely thoughtdisordered patients elicit attention far more easily than the Borderline whose social adaptivity, though marginal, can mask their true fragmentation. Yet Borderlines are at risk of hospitalization both for suicidal gestures and transient psychotic episodes. This is particularly true in a complex urban environment where the structure so badly needed by the Borderline -- familial, occupational, and intersocietal -- is not ready made.

Due to the Borderline's fragmentation, reconstruction leading to productivity may take years of psychotherapeutic intervention. The Borderline patient is quite often economically low functioning. Employment is possible in the guise of the "as if" personality but at best is unstable. Unfortunately, public mental health services such as case management, social and occupational self-help groups, and medication monitoring are currently restricted to schizophrenic and manic disorders. Therefore very few of the Borderline persons are receiving the treatment needed.

This study's results on distinctive facets of SCL-90 test performance, particularly if replicated in a variety of settings, could be useful in identifying the Borderline Personality Disorder at an early stage. Researchers and clinicians may have to work in conjunction to 
validate the Borderline Personality Disorder as severe enough to warrent public treatment services.

Summary

As noted by Gunderson \& Singer (1975), research on the Borderline Personality Disorder must be captioned in terms of who is describing the patient, in what context, how the samples were selected, and what data are collected. The results of this study can only address characteristics of the Borderline patient as he is conceived and diagnosed by the Providence Day Treatment Staff. This patient may be very different from Borderlines encountered in an inpatient setting or the community at large. Within this setting the samples studied were voluntary patients, thus Borderline persons whose acting-out behaviors were so anti-social as to lead to mandated treatment were eliminated. This sampling rule may partially explain the preponderance of women in the Borderline group studied.

Although the SCL-90 test performances were the only data studied, results do indicate promise of structured psychological testing contributing further to the understanding of Borderlines. In the at tempt to pinpoint Borderline's place on the continuum of mental and emotional disorders, future research would benefit from a multiple test-battery approach and a narrower delineation of diagnoses in comparison groups. 


\section{REFERENCES}

American Psychiatric Association. Diagnostic and statistical manual of mental disorders (3rd ed.). Washington, D.C.: Author, 1980.

Derogatis, L., Rickels, K., and Rock, A., The SCL-90: A step in the validation of a new self-report scale. British Journal of Psychiatry, 1976, 128, 280-289.

Deutsch, H. Some forms of emotional disturbance and their relationship to schizophrenia. Psychoanalytical Quarterly, 1942, 11, 301-320.

Grinker, R.R., Werble, B., \& Drye, R. The borderline syndrome: A behavioral study of ego functions. New York: Basic Books Inc., 1968.

Gunderson, J.G. and Singer, M.T. Defining borderline patients: An overview: American Journal of Psychiatry, 1975,132 (1), 1-10.

Gustin, Q.L., Goodpaster, W.A., Sajadi, C., Pitts, W.M., LaBasse, D.L., \& Snyder, S. MMPI characteristics of the DSM-III borderline personality disorder. Journal of Personality Assessment, 1983, 47 (1), 50-59.

Hays, W.L. Statistics for the social sciences. New York: Holt, Rinehart and Winston, Inc., 1973.

Hoch, P., and Cattell, J.P. The diagnosis of pseudoneurotic schizophrenia: Psychiatric Quarterly, 1959, 33, 17-43.

Hoch, P., Cattell, J.P., Strahl, M.O., and Pennes, H.H. The course and outcome of pseudoneurotic schizophrenia. American Journal of Psychiatry, 1962, 118, 106-115.

Hoch, P., and Polatin, P. Pseudoneurotic forms of schizophrenia. Psychiatric Quarterly, 1949, 23, 248-276.

Kernberg, 0. Borderline personality organization. Journal of the American Psychoanalytic Association, 1967, 15, 641-685.

Kernberg, 0 . Borderline conditions and pathological narcissism. New York: Jason Aronson, Inc, 1975,

Kernberg, 0. The structural diagnos is of borderline personality organization, In: Hartocollis, $P$. (Ed, ), Borderline personality disorders: The concept, the syndrome, the natient. New York: International Universities Press, Inc, , 1977, 87-121.

Klein, D.F. Importance of psychiatric diagnos is in the prediction of clinical drug effects, Archives of Gereral Psychiatry, 1367, 16, 118-126. 
Klein, D.F. Psychopharmacology and the borderline patient. In: Mack, J.E. (Ed.), Borderl ine states in psychiatry. New York: Grune \& Straton, Inc., 1975, 75-92.

Klein, M. Notes on some schizoid mechanisms. In: Riviere, J. (Ed.), Developments in psychoanalysis. London: Hogarth Press, 1946.

Knight, R. Borderline states. Bulletin of the Menninger Clinic, 1953, 17 (2), 1-12.

Rorschach, H. Psychodiagnostics. New York: Grune \& Stratton, 1975. (Originally published 1921).

Singer, M.H. The borderline diagnos is and psychological tests: Review and research, In: Hartocollis, P. (Ed.), Borderline personality disorders: The concept, the syndrome, the patient. New York: International Universities Press, Inc., 1977.

Snyder, S., Pitts, W.M., Goodpaster, W.A., Sajadi, C., \& Gustin, Q. MMPI profile of the DSM-III borderline personality disorder. American Journal of Psychiatry, 1982, 139 (8) 1046-1054.

Spitzer, R.L., Endicott, J., and Gibbon, M. Crossing the border into borderline personality and borderline schizophrenia: The development of criteria. Archives of General Psychiatry, 1978, $\underline{36}$ (1), $17-24$. 